MULTIMEDIA REVIEW

\title{
Managing the translation workflow with a Computer Assisted Translation Tool: SDL Trados 2011 \\ <http://www.sdl.com $>$
}

\section{Reviewed by Laura Ramírez Polo \\ Laura.Ramirez-Polo@uv.es \\ Universitat de Valencia, Spain}

\section{INTRODUCTION}

Over the past 30 years, translators have been continuously incorporating the new advances in technology into their daily work. Nowadays, it is inconceivable that a professional does not use a computer with at least a word processor and some tool allowing terminology to be managed and looked up, be it some application on the Internet or a simple spreadsheet.

However, most translators need more specific tools to cope with their daily work. Indeed, the idea of the translator's workstation incorporating all the features needed by a professional translator has been present since the 1960s, when the ALPAC report published in 1966 (ALPAC, 1966), which analysed the state of the art on Machine Translation, recommended the development of tools intended to aid, not to substitute, the translator.

Since then, a number of attempts ${ }^{1}$ have been made to define the ideal translator's workstation. With the quick expansion of desktop computers in the 1990s, the first commercial Computer-Assisted Translation (CAT) tools were born, such as Trados Workbench or Transit, and all of them have been incorporating these ideas until the present day, expanding their functionality as new needs arise.

\footnotetext{
${ }^{1}$ See Hutchins (1998: 293) for a review on the origins of the translator's workstation; Arthem (1978) explained the application of translation technology in the European Union; and Kay (1980/1997) wrote a seminal paper setting out the ideal design for a translator's workstation.
} 
The following review aims at analysing the next-to-last release ${ }^{2}$ of one of the most widely used tools in the world of professional translation, SDL Trados Studio 2011, focusing on the particular needs of professional translators. In order to do so, we will review the main components of a CAT Tool and will discuss the advantages and disadvantages of implementing this type of technology in the translation workflow. Subsequently we will describe the translation process using SDL Trados Studio 2011, dividing it into three phases: before, during and after the translation. The last part of this review offers some alternatives to SDL Trados Studio 2011, as well as some ideas for its application in the translation classroom.

\section{COMPONENTS OF A CAT TOOL}

Rico Pérez (2002) adapted the categorisation of tools proposed by Melby (1998) in order to outline the automated translation workflow, dividing it into three main phases: before, during and after translation. In each of these phases, different tools and different components of each tool are used. The idea behind a CAT Tool is to offer an all-round product that comprises most of the tasks carried out during these three phases. Therefore, most CAT tools include a series of main components or features that aim to satisfy the needs of the professional translator throughout the whole process. These can be summarised as follows ${ }^{3}$ :

- A Translation Memory System manages translation memories, that is, bilingual text files that contain segmented, aligned, parsed and classified texts (EAGLES, 1996). This component allows the creation, editing and deleting of translation units and whole translation memories. Besides, the system not only stores segmented texts, but also allows their retrieval when similar or identical texts need to be translated again.

- A Terminology Management System enables translators to create, edit and delete databases as well as concepts and terms within these databases. Edo (2011) carried out a review of different Terminology Management Systems integrated within CAT tools.

\footnotetext{
${ }^{2}$ The last versión of the software is SDL Trados 2014, which was released in July 2013.

${ }^{3}$ See Candel Mora and Ramírez Polo (in press) for a more detailed description of these components.
} 
- An Alignment Tool segments and aligns two bilingual texts that have not been processed with a CAT tool in order to integrate them into a translation memory. This may be useful to reuse previously translated material or to make use of bilingual texts coming from a reliable source.

- Editor. Though there are different categories of CAT tools and some of them use an external editor such as MS Word, there is a growing trend to endow them with their own editor. This editor usually only supports an intermediate format, which can be either proprietary or standardised, such as $\mathrm{XLIFF}^{4}$. Therefore, documents in various formats that are to be translated in the editor must undergo a transformation process in order to be ready for translation. The editor interacts with the translation memory and the terminology database, offering added functionalities such as pretranslation, assembly of subsegments, auto-propagation, active terminology recognition or concordance search.

Apart from these main components, CAT tools also include different utilities for quality management, such as a spellchecker, and controls to verify the correct use of terminology or whether tags, numbers and formatting issues have been placed correctly. Other more advanced features are related to project management. Though these features can vary greatly from system to system depending on the version and sophistication of the system, most CAT tools include some kind of statistics count in order to calculate the number of words, segments and characters to be translated, which allows the professional translator to prepare budgets and invoices, as well as to establish a date for delivery.

\section{ADVANTAGES AND DISADVANTAGES OF USING CAT TOOLS}

The use of this type of technology brings advantages and disadvantages with it. Bowker (2002: 114-125) reviewed the benefits and drawbacks of working with a Translation Memory System, including time, quality, electronic form, file formats, filters and standards, character sets and language-related difficulties, attitudes, rates of pay, ownership, integration with other tools and economic aspects.

\footnotetext{
${ }^{4}$ XLIFF is an XML-based format created to standardise localisation. XLIFF was standardised by OASIS in 2002. Its current specification is v1.2, released on Feb. 1, 2008.
} 
In summary, one of the main advantages of CAT tools claimed by the vendors is the ability to reuse previous translations, thus saving time, as well as to guarantee terminological consistency, given a well-built termbase. With regard to the drawbacks, some users might have difficulties in learning how to work with these tools due to their growing technical sophistication. Price can also be a hurdle, especially for novice translators and students that wish to get an insight into these applications.

Therefore, before acquiring and integrating this type of technology into the translation process, it is important to take into account a series of factors that might tip the balance in favour or against its acquisition. Ramírez Polo (2010) gives some advice on how to make a decision and summarises these factors as follows: the real need for such a tool, the direct or indirect obligation imposed by the customer or agency in order to be able to work, the price and how much the user is able to afford, the functionality of the tool, the formats that can be processed, the portability in different operating systems, the compatibility with other tools, the ease of use or usability, the community of users and social tools such as forums, blogs, Facebook groups, Twitter accounts, etc. that might be of help and finally the quality, availability and price of the customer service.

\section{SDL TRADOS STUDIO 2011}

SDL Trados Studio 2011 is a software package designed for professional translation. The history of the program dates back to 1984, when Jochen Hummel and Iko Knyphausen initially set up Trados as a Language Service Provider (LSP). However, it was not until 1992 when the first version of Translator's Workbench, a simple software application intended to help translators, was first released (SDL, 2012). In the following years the original software underwent considerable changes and in 2005 the company was acquired by the multilanguage provider SDL. After a number of attempts to market both Translator's Workbench and the proprietary $S D L X$ tool in a single software package or suite that still offered them as separate tools, in 2009 the company finally launched the first integrated version, which aimed to offer all the different functionalities in a single application with one consistent graphical user interface. SDL Trados Studio 2011 is an improved version of this first attempt. However, the Terminology Management System Multiterm (including the terminology database 
management system, a widget for desktop look-up and a utility to convert terminological data from other formats into Multiterm format) as well as the alignment component WinAlign and the recently acquired tool Passolo for the localisation of software are still single applications. Furthermore, they also offer a tool for terminology extraction that needs a separate licence. The price of SDL Trados Studio 2011 ranges from 99 Euro for the Starter Edition to 2195 Euro for the Professional version.

\section{TRANSLATION WORKFLOW WITH SDL TRADOS STUDIO 2011}

In the following sections we will review the functionalities of SDL Trados Studio 2011 as they are applied in the translation workflow. Upon program launch, a clean, functional interface (Home View) offers several view options (Editor, Translation Memory, Files, Reports), as well as a selection of the major tasks: open document, open package, new project, terminology management, align translated documents, etc. (Figure 1).

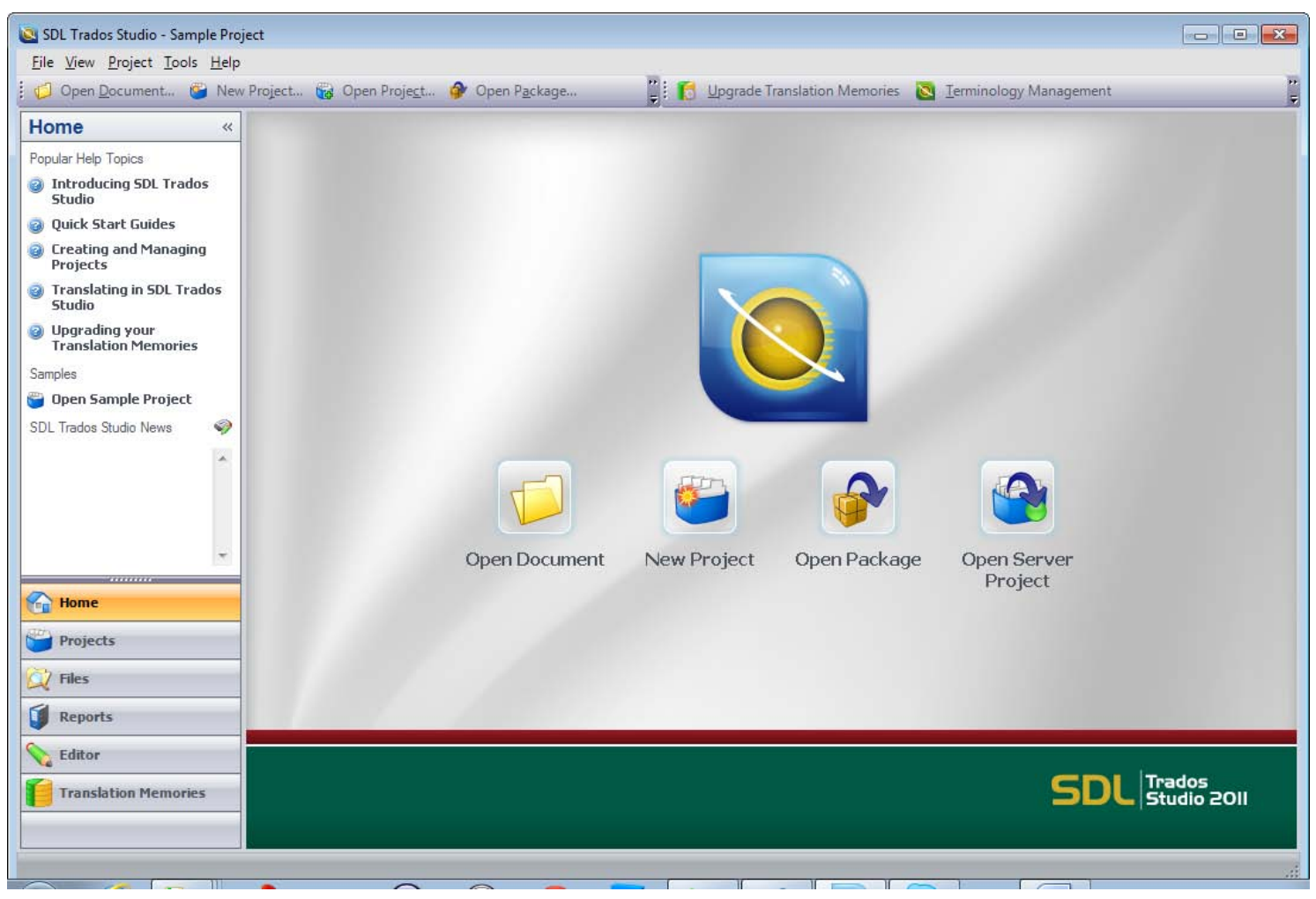

Figure 1. SDL Trados Studio 2011's start screen, which allows access to the most important procedures in the central panel. 


\section{1. First Stage: Before the Translation}

In the first stage, there are three main possibilities:

- The translator wants to translate a single file into one target language.

- The translator wants to translate a number of files into one or various target languages and creates a translation project.

- The translator receives a package from the agency or the customer, that is, a compressed file containing all the necessary components for the translation: translation memory, terminology databases (if available), files to be translated and, if necessary, reference files (such as reference PDF files or pictures).

The first case is rather infrequent, since even if only one file needs to be translated, a project is usually created containing a translation memory and, if available or necessary, a terminology database, which needs to have been created previously with Multiterm. The translation memory is usually either provided by the client (agency, direct customer) or created ad-hoc for the project. Machine Translation technology can also be used in the project.

In the creation of the project an assistant helps the user in the following steps:

- Choose whether a project should be based on a template, a previous project, or should be created from scratch.

- Provide project details: Name and location in the computer. Optionally the user can add a description and indicate the date and time the work is due and assign the project to a customer.

- Choose the project languages. The user needs to choose the source language and the target languages.

- Select the project files, that is, the files that are going to be translated. Reference files that might be of help for the translator can be added too.

- Select a translation memory or a machine translation engine. If no translation memories are available, the user can create one ad-hoc within the application. The integration of several MT engines is one of the novelties of Studio 2009 and 2011. 
- Add termbases. If the customer does not provide a termbase or there are none available, the user first needs to create one in a separate application, Multiterm.

- As a new feature, SDL Trados Studio 2011 incorporates the possibility of adding previously translated files for each translatable document in the project. The software will then extract the translation units and transfer them to the editor. This new feature is called PerfectMatch.

Once the project has been set up (Figure 2), the next step is to carry out a custom task sequence. This sequence can be adapted if needed, but typically it comprises the following tasks:

- Convert to a translatable format: Content and format from the original file will be separated and the documents will be converted into an intermediary file format which can be processed in the tool editor. SDL Trados Studio 2011 works with SDLXLIFF, a variant of XLIFF.

- Copy to target languages: Folders are created for each language pair and the intermediary files are copied in each of them. These files are bilingual, that is, they contain both the source and the target segments.

- Apply PerfectMatch: If bilingual files have been added, segments will be extracted and transferred to the file to be translated. These segments are then blocked in the editor, since they have already been reviewed and approved, without having to review them over and over again.

- Analyse files: A statistical account of the different files of the project is performed.

- Pre-translate files: Finally, the files are checked against the translation memory and, if there are any previous translations available, these will be introduced in the bilingual text and be visible when the file is opened in the editor. 


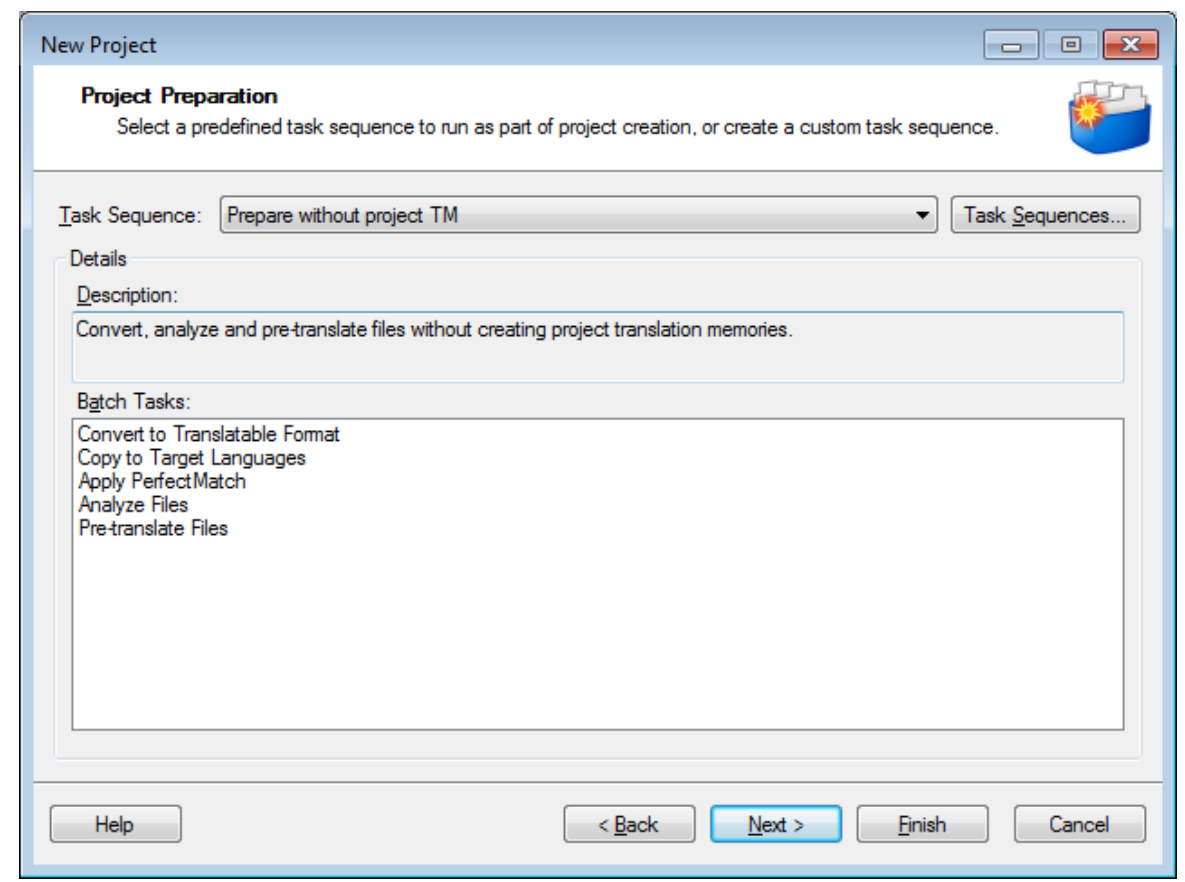

Figure 2. Project Setup.

Once the project has been prepared, first the translator checks the analysis and the pretranslation reports in order to determine how many words the files contain and, if there were any translation memories available, how many segments have already been translated. Subsequently she opens the files, one by one, that will be processed in the editor.

\section{2. Second Stage: During the Translation}

In a second stage, the translator starts her work. The editor has a table layout, where the source text is presented on the left-hand side and the translation is introduced on the right-hand side, as can be observed in Figure 3. The user moves sequentially from one segment to the next, either with the mouse, with the direction arrows or with a shortcut that confirms the segment to save it in the translation memory. Once it has been stored, it can be retrieved later if there is a similar or identical segment in the source document.

At this stage, the translator can make use of a wide range of options that help her to optimise her work. Some of the most interesting options offered by SDL Trados Studio 2011 are auto-propagation, active terminology recognition, concordance search, AutoSuggest, QuickPlace and real-time preview. In the following we will comment briefly on each of these features: 
- Auto-propagation: Segments that are identical or only differ in placeables (numbers, dates, measures, etc.) can be propagated automatically throughout the target text.

- Active Terminology Recognition: Terminology in the source text that is stored in a termbase is recognised. The translator can introduce this terminology either with a mouse click, a shortcut or by starting to type it.

- Concordance Search: The translator can look up the translation memory for terms or expressions while she is translating.

- AutoSuggest: As we can see in Figure 4, the user starts typing and the software suggests a word based on the termbase or on an AutoSuggest dictionary. In order to confirm and to introduce the word in the target text, the user only needs to confirm by pressing Enter.

- QuickPlace: This utility simplifies how to deal with formatting, tags, numbers, dates and all of those items that might not require translation or only need to be adapted in terms of format (e.g. automatically substituting “.” for “,” in numbers when translating from English into Spanish).

- Real-time preview: The translator has only a limited view of the document she is translating, since it has been segmented and put in a tabular format. However, SDL Trados Studio 2011 has a preview function that allows the user to see what the real final document will look like. 


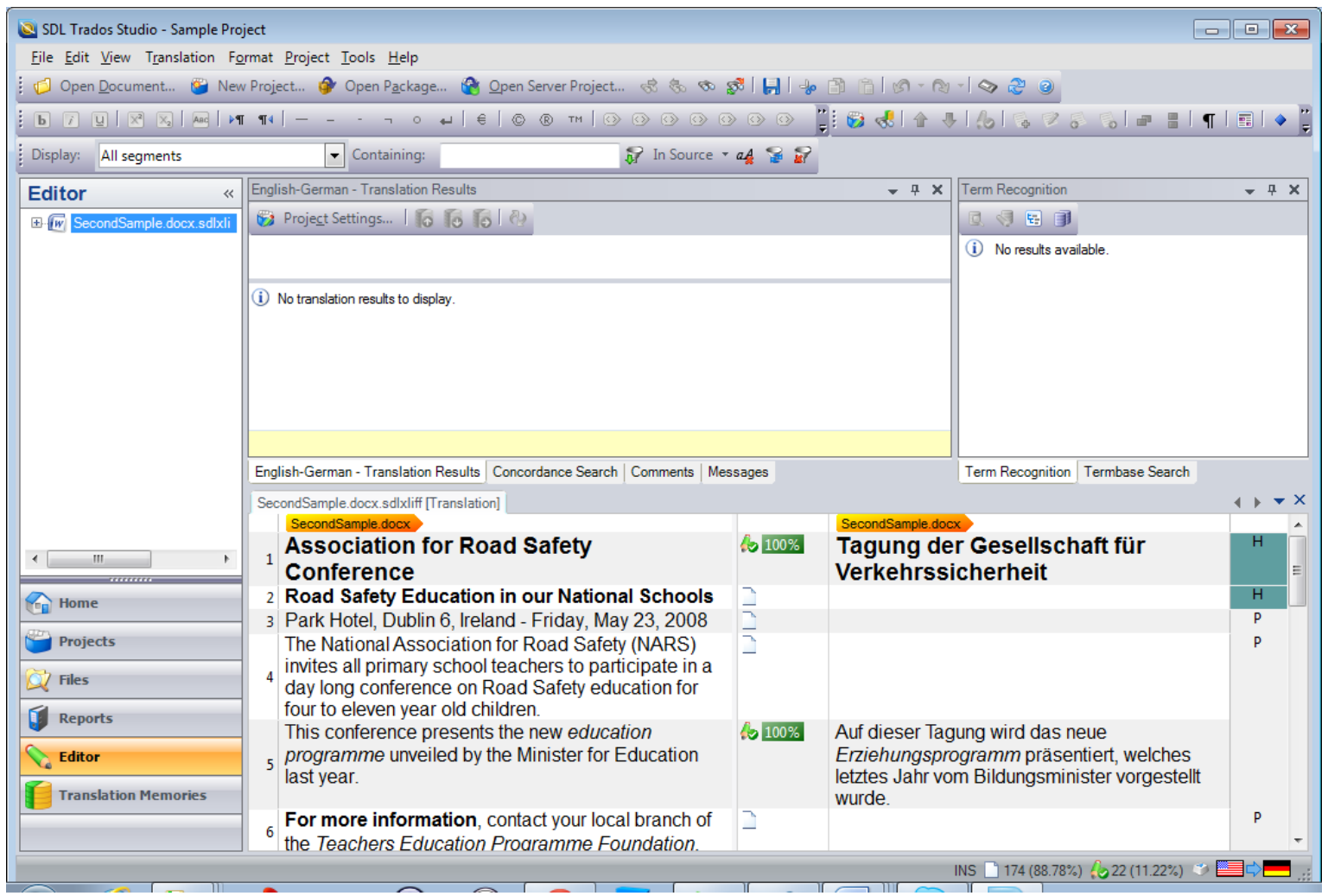

Figure 3. Editor Window in SDL Trados Studio 2011.

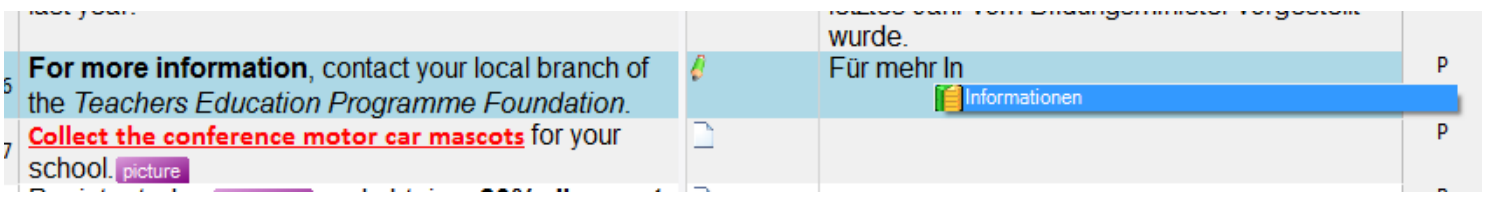

Figure 4. Example of the AutoSuggest technology.

\section{3. Third Stage: After the Translation}

In a final stage, the user has the possibility of conducting a quality check that comprises both a spell check and the verification of different aspects, such as tags, segments (if all have been translated, if source and target segments are identical), inconsistencies, punctuation, numbers or terminology, checking for the possible non-use of target terms, for instance. The verification settings can be configured in the project settings.

Furthermore, the translator can create a package for the reviewer, including the files, the translation memory and the termbase. During review, the reviewer can use the new feature Track changes, which is very similar to the utility offered in MS Word. Insertions are marked in a different colour, together with the initials of the reviewer and the time, and deletions are crossed out, in a Word-like manner. In addition, comments 
can be made. Once the text has been sent back to the translator, she can accept or reject the changes. If the reviewer does not have SDL Trados Studio 2011, there is also an interesting new feature that allows her to correct the document with the track changes utility in Word and re-import the corrected file back into SDL Trados Studio 2011. To do so, the translator needs to export the file for external review.

A final task that the translator might undertake once the translation has been reviewed is to update the main translation memories with the latest version of the target text, once it has been reviewed and approved.

\section{ALTERNATIVES TO SDL TRADOS STUDIO 2011}

Even though SDL Trados Studio 2011 is one of the most widely used tools on the market, there are a number of alternatives, including Déjà Vu, Transit, Wordfast, MemoQ and Across, to name just a few. However, it is difficult to establish a comparison among all of them, since there is a great deal of variation depending on the version and the type of licence. Peris (2010) offers a comparison with the strengths and weaknesses of some of the subscription-based low-cost versions of these CAT tools.

Another interesting alternative is OmegaT, a free software application which offers the basic functionalities of a CAT Tool: translation memory and dictionary management. This might be an alternative for novice translators or students who want to start using this type of technology in their processes. However, usually free software tools or lowcost versions of CAT Tools do not offer all the necessary functionalities and lack usability. Furthermore, though most tools currently support TMX and XLIFF formats, which are standards for the transfer of translation memories and localisation files among different systems, there are still inconsistencies in the application of these standards. Besides, most customers, especially translation agencies, "oblige" translators to use a certain software application, dismissing all other alternatives.

\section{APPLICATION IN THE CLASSROOM}

Although SDL Trados Studio 2011 is a tool intended for professional use, it is not uncommon to find practical applications of CAT tools in the classroom. Some of these 
are depicted in Suau Jiménez and Ramírez Polo (2010) and Ramírez Polo and Ferrer Mora (2010).

Basically, this type of technology can be implemented in four types of courses:

- Translation technology courses, based on the training of instrumental skills. Here the CAT tool is the main player and students learn the technical aspects of its functioning.

- Translation courses, based on the training of translation skills. Students use the CAT tool as an instrument in order to practise translation in an environment close to the one they can expect to find in professional practice.

- Terminology courses, based on the training of terminological skills. As in translation courses, students use the Terminology Management module of a CAT tool as an instrument to practise terminology management in an environment close to the one they can expect to find in professional practice.

- Management courses, based on the training of management skills. Students learn to use the management utilities of a CAT tool to carry out a translation project and thus learn how to work in a professional way.

SDL Trados Studio 2011 offers all these possibilities and can constitute a very enriching complement in the training of future translators because of its applicability in professional practice. Furthermore, the company offers academic licences and has an academic programme for trainers, with materials and certifications for those who join it.

\section{CONCLUSIONS}

In this review, in general, we have dealt with the use of CAT Tools to manage the translation workflow and, more particularly, we have described how SDL Trados Studio 2011 works.

In my opinion, the last release of this software package constitutes one of the most complete CAT tools available on the market and offers a wide range of functionalities that help the translator to optimise her work. Furthermore, including this type of technology in the classroom can bring students closer to real professional practice and offer them a competitive advantage against other future translators who have not been trained in the use of this software. It is important to note, however, that the acquisition 
of such applications implies a considerable outlay and that a number of factors have to be considered before deciding to acquire a licence.

\section{REFERENCES}

ALPAC 1966. "Language and Machines - Computers in Translation and Linguistics” A report by the Automatic Language Processing Advisory Committee, Division of Behavioral Sciences. Washington, DC: National Academy of Sciences, National Research Council.

Arthern, P.J. 1978 "Machine translation and computerized terminology systems: a translator's viewpoint”. In Snell, B.N. (Ed.) Translating and the Computer: Proceedings of a Seminar. London, UK: North-Holland Publishing Company, 77108.

Bowker, L. 2002. Computer-Aided Translation Technology: A Practical Introduction. Ottawa: University of Ottawa Press.

Candel Mora, M.A. and Ramírez Polo, L. 2012. “Translation technology in institutional settings: a decision-making framework towards the implementation of computer-assisted translation systems”. Paper presented at International T3L Conference: Tradumatica, Translation Technologies \& Localization. Barcelona. 21- 22 June 2011.

EAGLES MT Evaluation Working Group 1996. EAGLES Evaluation of Natural Language Processing Systems. Final Report. EAGLES Document EAG-EWGPR.2. Copenhagen, 271.

Edo Marzá, N. 2011. “Terminology Management Systems for the development of (specialised) dictionaries: A focus on WordSmith Tools and Termstar XV". Language Value 3, 162-173.

Hutchins, J. 1998. “The origins of the translator's workstation”. Machine Translation 13 (4), 287-307.

Kay, M. 1980/1997. “The proper place of men and machines in language translation”. Machine Translation 12 (1-2), 3-23. 
Melby, A. 1998. "Eight types of translation technology". Paper presented at the American Translators Association (ATA) 39th Annual Conference. 10 September $2012<$ http://www.ttt.org/technology/8types.pdf $>$

Peris, N. 2010. “Cheap translation tech: Who does what...and for how much?” 10

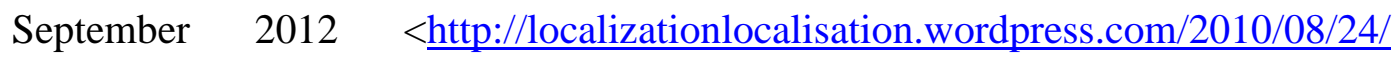
cheap-translation-tech-who-does-what-and-for-how-much/>

Ramírez Polo, L. 2010: “¿Qué me pongo? 10 consejos para adquirir una herramienta TAO”. 10 September 2012 <http://laurapo.blogs.uv.es/\%C2\%BFque-me-pongo10-consejos-para-adquirir-una-herramienta-tao/>

Ramirez Polo, L. and Ferrer Mora, H. 2010. “Aplicación de las TIC en Traducción e Interpretación en la Universidad de Valencia: experiencias y reflexiones”. Redit 4, 23-41.

Rico, C. 2002. "El perfil del traductor profesional. Desarrollo de competencias para una rápida incorporación a la industria”. In Simposi sobre l'Ensenyament a Distància i Semipresencial de la Tradumàtica. Bellaterra, Catalunya, 1er, 8 pages. 10 September 2012 < $\underline{\text { http://ddd.uab.cat/pub/poncom/2002/64981/pertraproiSPA.pdf }>}$

SDL. "The history of SDL. Celebrating innovation in the translation memory industry". 10 September 2012 < http://www.translationzone.com/en/about-us/history-of-sdl$\underline{\text { trados} />}$

Suau Jiménez, F. and Ramírez Polo, L. 2010. "Las condiciones profesionales del traductor especializado: propuesta basada en las TIC”. In García, M., P. Ribera, A. Costa, M.D. García, P. García, A. Iglesias, M. del Pozo and C. Rodríguez (Eds.) Interacció Comunicativa i Ensenyament de Llengües. Valencia: Universitat de València (PUV), 469-476.

Waßmer, T. 2011. "SDL Trados Studio 2011. Reviewed by Thomas Waßmer". Multilingual 22(8), 14-19.

Received: 12 September 2012 